PNL $-430 \%$

NUREG/CR-2765

PNL-4301

RAE-18-2

\title{
A Mathematical Model for Radon Diffusion in Earthen Materials
}

Prepared by K. K. Nielson, V. C. Rogers/RAE

Rogers \& Associates Engineering Corporation

Pacific Northwest Laboratory

Prepared for

U.S. Nuclear Regulatory

Commission 


\section{NOTICE}

This report was prepared as an account of work sponsored by an agency of the United States Government. Neither the United States Government nor any agency thereof, or any of their employees, makes any warranty, expressed or implied, or assumes any legal liability of responsibility for any third party's use, or the results of such use, of any information, apparatus, product or process disclosed in this report, or represents that its use by such third party would not infringe privately owned rights.

\section{Availability of Reference Materials Cited in NRC Publications}

Most documents cited in NRC publications will be available from one of the following sources:

1. The NRC Public Document Room, 1717 H Street, N.W. Washington, DC 20555

2. The NRC/GPO Sales Program, U.S. Nuclear Regulatory Commission, Washington, DC 20555

3. The National Technical Information Service, Springfield, VA 22161

Although the listing that follows represents the majority of documents cited in NRC publications, it is not intended to be exhaustive.

Referenced documents available for inspection and copying for a fee from the NRC Public Document Room include NRC correspondence and iriternal NRC memoranda; NRC Office of Inspection and Enforcement bulletins, circulars, information notices, inspection and investigation notices; Licensee Event Reports; vendor reports and correspondence; Commission papers; and applicant and licensee documents and correspondence.

The following documents in the NUREG series are available for purchase from the NRC/GPO Sales Program: formal NRC staff and contractor reports, NRC-sponsored conference proceedings, and NRC booklets and brochures. Also available are Regulatory Guides, NRC regulations in the Code of Federal Regulations, and Nuclear Regulatory Commission /ssuances.

Documents available from the National Technical Information Service include NUREG series reports and technical reports prepared by other federal agencies and reports prepared by the Atomic Energy Commission, forerunner agency to the Nuclear Regulatory Commission.

Documents available from public and special technical libraries include all open literature items, such as books, journal and periodical articles, and transactions. Federal Register notices, federal and state legislation, and congressional reports can usually be obtained from these libraries.

Documents such as theses, dissertations, foreign reports and translations, and non-NRC conference proceedings are available for purchase from the organization sponsoring the publication cited.

Single copies of NAC draft reports are available free upon written request to the Division of Technical Information and Document Control, U.S. Nuclear Reguiatory Commission, Washington, DC 20555.

Copies of industry codes and standards used in a substantive manner in the NAC regulatory process are maintained at the NRC Library, 7920 Norfolk Avenue, Bethesda, Maryland, and are available there for reference use by the public. Codes and standards are usually copyrighted and may be purchased from the originating organization or, if they are American National Standards, from the American National Standards Institute, 1430 Broadway, New York, NY 10018. 
NUREG/CR-2765

PNL-4301

RAE-18-2

RU

\section{A Mathematical Model for Radon Diffusion in Earthen Materials}

Manuscript Completed: March 1982

Date Published: October 1982

Prepared by

K. K. Nielson, V. C. Rogers, RAE

Rogers \& Associates Engineering Corporation

P. O. Box 330

Salt Lake City, UT 84110

Under Subcontract to

Pacific Northwest Laboratory

Richland, WA 99352

\section{Prepared for}

Division of Health, Siting and Weste Management

Office of Nuclear Regulatory Research

U.S. Nucleer Regulatory Commission

Washington, D.C. 20555

NRC FIN B2269 

Radon migration in porous, earthen materials is characterized by diffusion in both the air and water components of the system as well as by the interaction of the radon between the air and water. The size distribution and configuration of the pore spaces and their moisture distributions are key parameters in determining the radon diffusion coefficient for the bulk material. A mathematical model is developed and presented for calculating radon diffusion coefficients solely from the moisture content and pore size distribution of a soit, reducing the need for resorting to radon diffusion measurements. The resulting diffusion coefficients increase with the median pore diameter of the soil and decrease with increasing widths of the pore size distribution. The calculated diffusion coefficients are suitable for use in simple homogeneous-medium diffusion expressions for predicting radon transport and compare well with measured diffusion coefficients and with empirical diffusion coefficient correlations. 

TABLE OF CONTENTS

Section

Page

INTRODUCTION . . . . . . . . . . . . . . . . . . . . . . . . 1

PREVIOUS STUDIES . . . . . . . . . . . . . . . . . . 2

SCOPE OF PRESENT WORK . . . . . . . . . . . . . . . . . . . 3

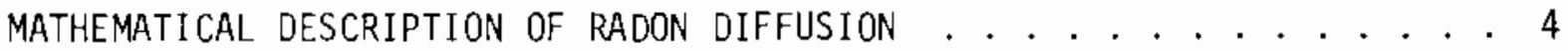

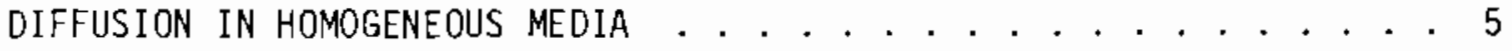

DIFFUSION IN TWO-PHASE MEDIA . . . . . . . . . . . . . . . . . 11

PORE MOOEL DEVELOPMENT . . . . . . . . . . . . . . . . . . 15

PORE FLUID CONFIGURATION . . . . . . . . . . . . . . . 15

PORE STRUCTURE ............................ . . . 21

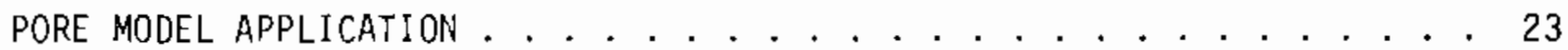

DETERMINATION OF SOIL PARAMETERS . . . . . . . . . . . . . . . . 24

CALCULATIONS .......................... . . . 26

RESULTS . . . . . . . . . . . . . . . . . . . 27

Sensitivity to Particle Size Parameters . . . . . . . . . . . . 27

Comparison with Measured Data . . . . . . . . . . . . . . . . 28

Comparison with Published Correlations . . . . . . . . . . . 32

CONCLUSIONS . . . . . . . . . . . . . . . . . . . . 36

LITERATURE REFERENCES . . . . . . . . . . . . . . . . . . . 38 


\section{LIST OF FIGURES}

Figure No.

$\underline{\text { Tit]e }}$

Page

Figure 1. Reference Volume of Unsaturated Porous Material . . . . . . 6

Figure 2. IlTustration of Definitions of Radon Diffusion Coefficients. . . . . . . . . . . . . . . 8

Figure 3. Comparison of Diffusion Coefficients for Water-Blocked Pores, $\mathrm{D}_{b}$, and Unblocked Pores, $\mathrm{D}_{u}$, with Measured Diffusion Coefficients . . . . . . . . . . . . . . . 18

Figure 4. Illustration of Pore Combinations for a Three-Component Pore Size Distribution . . . . . . . . . . . . . . 22

Figure 5. Comparison of Diffusion Coefficient - Moisture Curves For Various Median Pore Sizes............. . 30

Figure 6. Comparison of Diffusion Coefficient - Moisture Curves For Varying Widths of Pore Size Distributions . . . . . . . . 31

Figure 7. Comparison of Measured Radon Diffusion Coefficients with Calculated Values................ . . 33

Figure 8. Comparison of Diffusion Coefficients for Water-Blocked Pores, $D_{b}$, and Unblocked Pores, $D_{u}$, with Empirical Correlations with Air-Filled Porosity (A) and Moisture (B), and with the Range of Calculated D's for Eight Soils. 35 


\section{LIST OF TABLES}

Table No.

Table I. Pore Size Distributions Used for Diffusion Coefficient Sensitivity Tests... . . . . . . . . . . . . . 29 


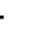




\section{ACKNOWLEDGEMENTS}

The authors appreciate the helpful technical discussions with the project manager, W.B. Silker, and with G.W. Gee, both of Pacific Northwest Laboratory, and with M.W. Grant of Rogers and Associates Engineering Corp. 



\section{INTRODUCTION}

Radon emissions from uranium mill tajlings have iong been recognized as a potential health hazard. Consequently, an important feature of any uranium mill tailings management program is the proper long-term stabilization of the tailings to adequately reduce radon emissions. The generally accepted means of achieving stabilization is to cover the tailings with earthen materials. Since radon is a chemically inert gas whose principal isotope, ${ }^{222} \mathrm{Rn}$, has a radioactive halfTife of 3.8 days, it can migrate considerable distances through earthen materials before decaying to a solid daughter product. The earthen cover must therefore be of sufficient thickness to contain the radon throughout several half-lives in order to minimize the fraction which ultimately escapes into the atmosphere. The thickness of cover required to reduce the flux of escaping radon to a given level can be calculated from the radon diffusion coefficient of the cover material.

Radon diffusion coefficients for earthen materials have traditionally been determined from laboratory measurements with the subject soil at a prescribed moisture content and compaction. However, it is often desirable to estimate the diffusion coefficient of materials under varying conditions for which measured values are not available. The Nuclear Regulatory Commission (NRC) has used a simple correlation of diffusion coefficient with moisture ${ }^{(1)}$ to predict required earthen cover thicknesses in their Generic Environmental Impact State-

ment (GEIS) on Uranium Milling. ${ }^{(2)}$ It is recognized, however, that moisture profiles are variable, and that soil compaction, texture, and other parameters also have a significant influence on diffusion coefficients. Therefore, it is desirable to develop a mathematical model to describe the radon diffusion coefficient from basic soil parameters rather than predicting it from empirical correlations. The present model was developed for NRC under a subcontract with Battelle 
Pacific Northwest Laboratory to provide the necessary mathematical description of the radon diffusion process to accurately predict radon diffusion coefficients from basic soil parameters.

\section{Previous Studies}

Researchers have long been interested in the diffusion and transport of radon through porous materials. Early studies of radon in the natural environment ${ }^{(3-13)}$ have been supplemented by research dealing specifically with the diffusion and transport of radon produced in uranium mill tailings $(11,14-16)$ and ore minerals. $(17,18)$ In particular, References 3 and 19 contain excellent reviews of the general topic, and an excellent survey of the early Russian literature is given in Reference 20 . The early studies concerned with the diffusion of radon from uranium mill tailings were based on experiments with the diffusion of radon through tailings, soil and coricrete. Measurements made during these experiments were compared with diffusion theory and from the comparison, diffusion coefficients were deduced. In other laboratory experiments, $(1,21,22)$ the diffusion of radon through various tailings and cover materials was measured. Diffusion coefficients were deduced from both radon fluxes and from radon gas concentration profiles. Rapid transient methods for measuring radon diffusion coefficients have also been recently reported. $(23,24)$

Two recent field tests $(25,26)$ using uranium tailings materials also have yielded information associated with the diffusion coefficient. In one test (25) surface radon fluxes were measured for various thicknesses of a cover material placed over a small plot of tailings. The diffusion coefficient obtained from a least-squares fit of the flux data was consistent with the laboratory measurement on similar material. In the other field measurement $(26)$ the diffusion 
coefficient was deduced from in-situ borehole logging of the ${ }^{226} \mathrm{Ra}$ and ${ }^{222} \mathrm{Rn}$ concentrations in acidic and alkaline tailings. Additional field measurements are in progress for a variety of single and multilayer earthen and synthetic covers, $(27,28)$ and laboratory measurements of diffusion coefficients in similar multilayer systems have also been reported. (24)

One common feature pervades the bulk of the literature on radon diffusion in earthen materials and that is the necessity of basing the determination of the diffusion coefficient upon experimental radon measurements. Although these measurements are usually time-consuming and cumbersome, nevertheless, they allow for the accommodation of other mechanisms and uncertainties not explicitly quantified in the diffusion theory formalism.

In order to predict the diffusion coefficient of radon from physical properties of an earthen material without conducting radon measurements, two simple correlations have been proposed. One of these is the correlation with moisture ${ }^{(1)}$ which was used in the GEIS on uranium milling. (2) The other is a correlation with the air-filled porosity of the soil. (29) Similar functions of air-filled porosity have been used with other soil gases in agricultural applications. (30) Although these correlations permit estimation of diffusion coefficients from soil properties rather than diffusion measurements, their basis is still a series of measured values of diffusion coefficients.

\section{Scope of Present Work}

This report describes the mathematica] framework and methodology for estimating radon diffusion coefficients without relying on fitted parameters to radon diffusion data. The formalism considers the detailed composition of the pore fluid as weil as a statistical definition of the pore structure. The 
pore fluid is modeled as a two-phase mixture of air and water, with radon diffusion occurring in both phases, and with radon exchange occurring between the air and water. The pore structure is modeled from the measured pore size distribution of the soil, and is described by the weighted average of all combinations of single and composite pores. The soil parameters required to estimate a radon diffusion coefficient are thus the moisture, the packing density, and the pore size distribution.

The following sections contain a mathematical description of radon diffusion in both homogeneous and two-phase media, the development of a complex pore model, and the application of the model to real soils. The model development section includes descriptive soil parameters, open and water-blocked pore models, a description of moisture distribution in the various pores, a random pore combination model, and a description of pore blockage as saturation is approached. The application section discusses determination of pore size distributions, the computer code used to calculate the diffusion coefficients, the results of varying parameters and comparisons with measured diffusion coefficients.

\section{MATHEMATICAL DESCRIPTION OF RADON DIFFUSION}

Radon diffusion in soils occurs in both the air-filled and water-filled regions of pore space. Similar diffusion equations can be used to describe each phase, which can be combined with appropriate distribution coefficients to describe the dual system. The diffusion equations are described below for a single phase system, and are then combined in describing the water-air mixture for soil pores. 


\section{Diffusion in Homogeneous Media}

In diffusion theory the diffusion coefficient is defined by Fick's law, which relates the radon flux to the radon concentration gradient. For onedimensional diffusion this is

$$
J=-D_{e}(\partial C / \partial x)
$$

where

$J=$ radon flux from the bulk porous material $\left(\mathrm{pCi} / \mathrm{cm}^{2} \mathrm{~s}\right)$

$C=$ radon concentration in the total pore space of the material $\left(\mathrm{pCi} / \mathrm{cm}^{3}\right)$

$D_{e}=$ effective bulk diffusion coefficient of the porous material $\left(\mathrm{cm}^{2} / \mathrm{s}\right)$

Lack of uniformity exists in the literature with respect to the appropriate diffusion coefficient to use in predicting radon migration. The confusion arises from differing definitions of $\mathrm{C}$ and $\mathrm{J}$ as well as from the nature of common radon measurement methods. Radon concentrations sampled from within the soil are interstitial quantities, and hence the concentrations are measured per unit volume of pore. Conversely, the radon flux is measured across the total or bulk soil surface and not just across the exposed interstices ${ }^{(11)}$. Figure 1 illustrates these bulk and interstitial quantities for a schematic cross section of a soil. 


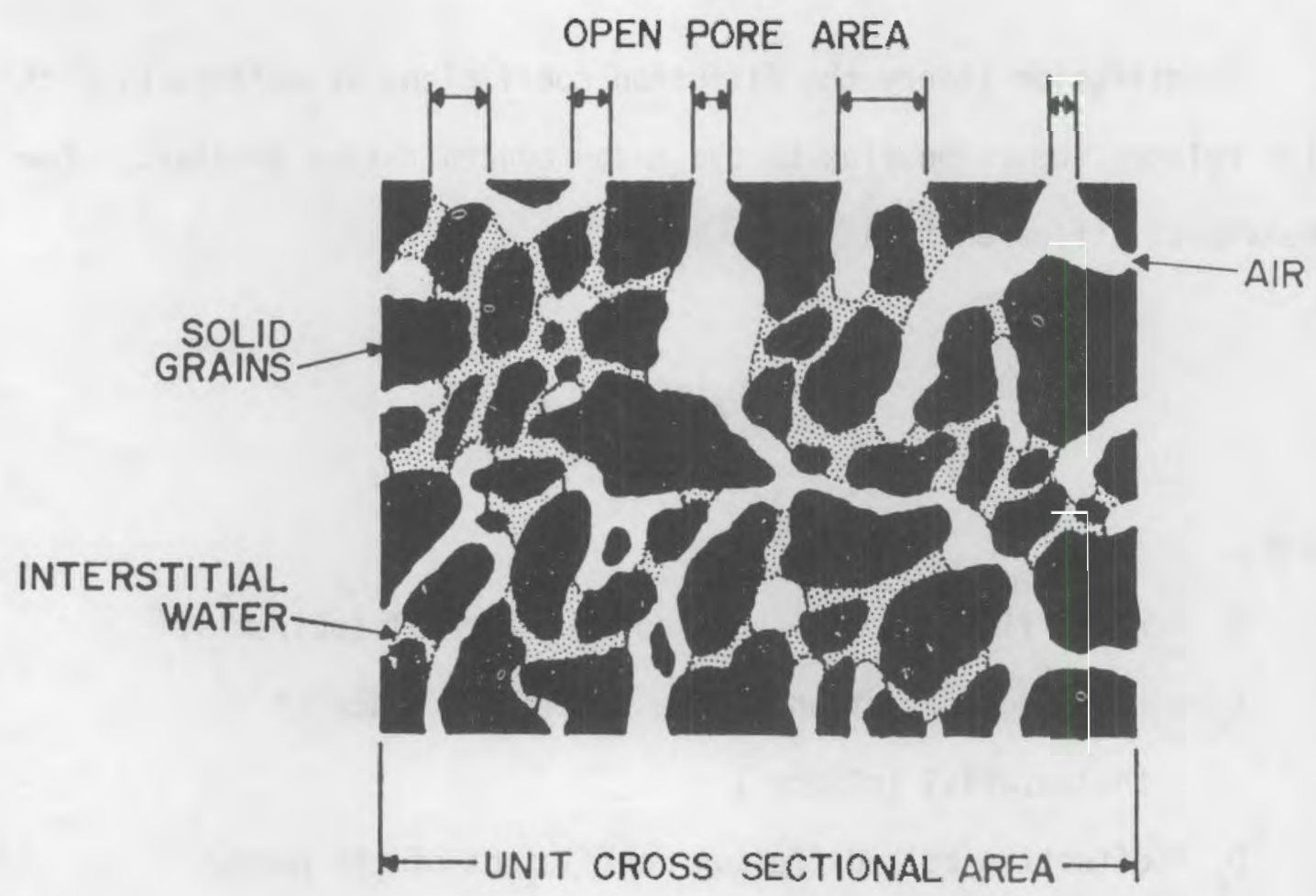

RAE - 100169

FIGURE 1. REFERENCE VOLUME OF UNSATURATED PORCUS MATERIAL.

Use of $\mathrm{D}_{\mathrm{e}}$ to relate the radon concentration gradient in the pore space to the bulk flux, J, accounts for the restricted nature of the channels in which diffusion occurs in the porous medium. In comparison to diffusion in a continuous or homogeneous medium, the two main factors which reduce the radon flux from a porous material are the reduction in cross-sectional area for diffusion, and secondly, the lengthening of the pathway for diffusion due to the circuitous nature of the pores. (14)

It is often helpful to refer to the radon diffusion coefficient of the 
interstitial or pore space when describing radon diffusion through a porous earthen material. The diffusion coefficient of the pore fluid can be shown to be related to the effective bulk diffusion coefficient by

$$
D=D_{e} / P,
$$

where $D=$ diffusion coefficient of the pore fluid $\left(\mathrm{cm}^{2} / \mathrm{s}\right)$

$P=$ total porosity of the porous medium.

The pore diffusion coefficient is defined from Fick's law as

$$
j=-D(\partial C / \partial x)
$$

where $j=$ radon flux in the pore space $\left(\mathrm{pCi} / \mathrm{cm}^{2} \mathrm{~s}\right)$. Although $j$ is not a measurable quantity, it can be visualized from Figure 1 as the radon flux per unit open-pore area. It is related to the measurable flux per unit area of the bulk soil by

$$
\mathrm{J}=\mathrm{Pj} \text {. }
$$

In order to clearly visualize the foregoing definitions of diffusion coefficients and also those which follow, Figure 2 illustrates these definitions. As illustrated, the measurable pore diffusion coefficient, D, may be a complicated function of various configurations such as air-filled channels, air and water regions, and water-blocked channels. However, in the respective limits of complete dryness or complete saturation, D may be related to the bulk diffusion coefficients of air or water by

$$
D_{a}=\tau D_{A}
$$




\section{BULK RADON DIFFUSION COEFFICIENTS}
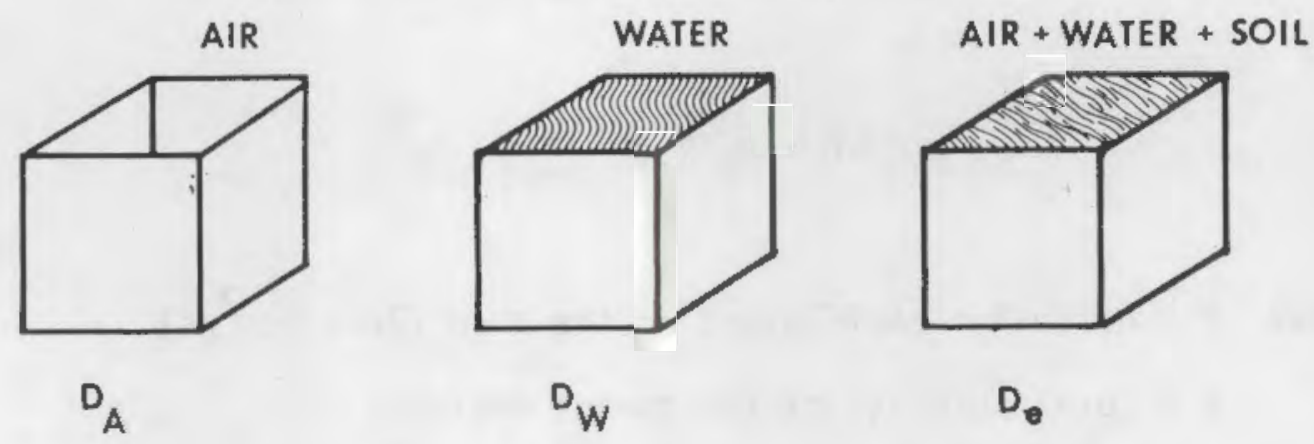

\section{PORE RADON DIFFUSION COEFFICIENTS}

AIR ONLY

$\left(\begin{array}{l}\text { water acts as } \\ \text { additional rock }\end{array}\right)$

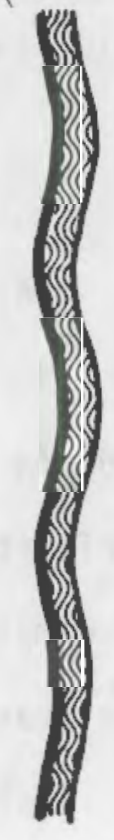

$D^{\prime}$

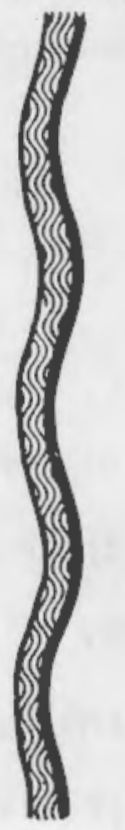

\section{RAE - 100333}

FIGURE 2.
AIR + WATER

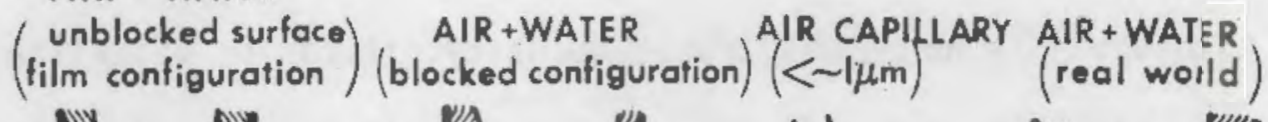

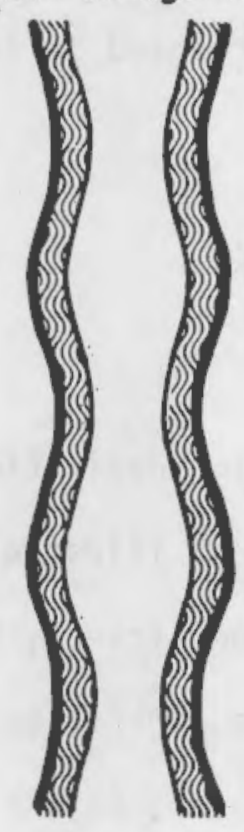

$\mathrm{D}_{\mathbf{v}}$

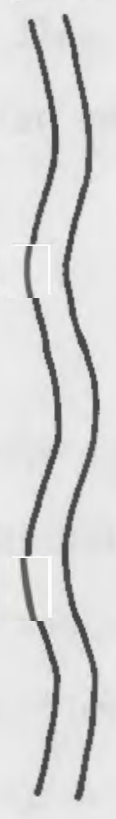

$\mathbf{D}_{\mathbf{k}}$

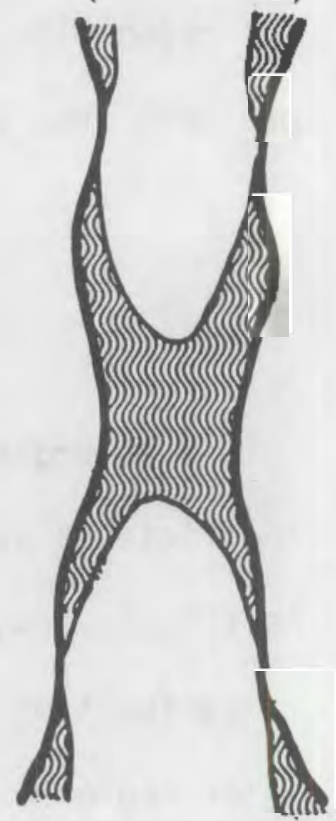

D

\section{ILLUSTRATION OF DEFINITIONS OF RADON DIFFUSION COEFFICIENTS}


and

$$
D_{W}=\tau D_{W}
$$

where $D_{a}=$ pore radon diffusion coefficient in a dry, air-filled porous medium $\left(\mathrm{cm}^{2} / \mathrm{s}\right)$

$D_{w}=$ pore radon diffusion coefficient in a water-saturated porous medium $\left(\mathrm{cm}^{2} / \mathrm{s}\right)$

$\tau=$ tortuosity of the porous medium $=\left(L / L_{e}\right)^{2}, L=$ bulk medium thickness, $L_{e}=$ diffusion path length. A typical value of $\tau$ is 0.66 , as obtained for uniform close-packed spheres. $D_{A}=$ radon diffusion coefficient of pure $\operatorname{air}^{(31)}\left(0.11 \mathrm{~cm}^{2} / \mathrm{s}\right)$

$D_{W}=$ radon diffusion coefficient of pure water ${ }^{(3)}\left(10^{-5} \mathrm{~cm}^{2} / \mathrm{s}\right)$

Reference 14 contains an excellent review of the nomenclature and definitions of the diffusion coefficients reported in the literature prior to 1976 , which are consistent with the present definitions. However, a recent pertinent review article ${ }^{(19)}$ gives a relationship different than that in Equation 2.

While most authors $(3,12,14,22,23,32)$ describe radon diffusion and the associated Fick's law relationship using the radon concentration in the pore space, $C$, some authors $(11,33)$ use the radon concentration per unit volume of bulk porous material. These two are simply related by

$$
c_{e}=P C
$$

where $\mathrm{C}_{\mathrm{e}}=$ radon concentration in the bulk porous soil medium $\left(\mathrm{pCi} / \mathrm{cm}^{3}\right)$. Substitution of Equations 2 and 7 into Equation 1 yields the following interesting result: 


$$
J=-D\left(\partial C_{e} / \partial x\right)
$$

Therefore, when the gradient of $C_{e}$ is related to the bulk radon flux, the diffusion coefficient of the fluid in the pore space is obtained.

An explicit consideration of radon migration only through the air-filled component of the pore space ${ }^{(29)}$ utilized the following Fickian relation:

$$
J=-D_{e}^{\prime}\left(\partial C_{a} / \partial x\right),
$$

Where $c_{a}=$ radon concentration in the gas-filled pore space.

At dryness or low moistures, $C_{a}$ is similar to $C$, so that $D_{e}^{\prime}$ is similar to $D_{e}$. At high moistures, the assumption that radon only diffuses in the air-filled pore space becomes questionable and it is more difficult to relate $D_{e}^{\prime}$ and $D_{e}$. The subject and implications of radon diffusion in only the air-filled pore space are still under investigation.

When Fick's law relationships are incorporated into the radon balance equation, the form of the diffusion equation containing $D_{e}$ will also contain an explicit reference to the porosity of the bulk material, while in the balance equation containing $D$, explicit reference to the porosity only occurs in the source term for those materials containing sources. Because of this feature, the remainder of the present discussion will utilize only pore diffusion coefficients, $D$, not $D_{e}$. Subscripts that will be associated with the pore diffusion coefficients refer to specific values or specific models for $D$, as illustrated in Figure 2. 


\section{Diffusion in Two-Phase Media}

Radon diffusion through a two-phase medium in the pore spaces of earthen materials involves several complex processes. There is radon diffusion through the air in the presence of a water layer. There is radon diffusion through the water in water-blocked pore regions, and there is radon absorption in the water, as well as other mechanisms. The general objective of the present effort is to characterizize these mechanisms which occur on a microscopic scale by a single macroscopic diffusion coefficient which can be used to describe the radon diffusion as if occurring through a simple homogeneous medium characteristic of the porous material.

Before proceeding with the differential equation describing diffusion, it is instructive to discuss the nature of the source term, Q. In general it is given by:

$$
Q=R E \rho \lambda / P,
$$

where $Q=$ volumetric radon source strength $\left(\mathrm{pCi} / \mathrm{cm}^{3} \mathrm{~s}\right)$

$\mathrm{R}=$ specific radium activity ( $\mathrm{pCi} / \mathrm{g}$ dry mass)

$E$ = emanation coefficient ( $\mathrm{pCi}$ released into pores/total $\mathrm{pCi}$ produced)

$\rho=$ dry density of material $\left(\mathrm{g} / \mathrm{cm}^{3}\right)$

$\lambda=$ decay constant for radon $\left(2.1 \times 10^{-6} \mathrm{~s}^{-1}\right)$

When considering the emanation of radon into the pore space, the question arises of whether the emanation occurs into the air or water-filled component of the space. Emanation has been measured and modeled for both rock-air and rock-water interfaces, and also described for intermediate, partially-saturated systems $^{(34)}$. Reference 34 also contains a comprehensive bibliography on the 
effects of moisture on radon emanation and diffusion. In general the total $E$ increases linearly with moisture from a value of $E_{a}$ until a plateau moisture $m^{*}$ is reached, at which point $E$ remains a constant $E_{W}$ until the material is saturated. The air and water components of E can be described by the following relationships:

$$
E=E_{a i r}+E_{\text {water }} \text {, }
$$

where $E_{a i r}$ is the fraction of the radon generation that occurs in the air component of the pore space and $E_{\text {water }}$ is the fraction of the radon that occurs in the water component of the pore space. The $E_{a i r}$ and $E_{\text {water }}$ terms are given by:

$$
\begin{aligned}
& E_{\text {water }}= \begin{cases}\frac{m}{m^{*}} E_{w} & \text { for } m<m^{*} \\
E_{w} & \text { for } m>m^{*}\end{cases} \\
& E_{\text {air }}= \begin{cases}E_{a}\left(1-m / m^{*}\right) & \text { for } m<m^{*} \\
0 & \text { for } m>m^{*}\end{cases}
\end{aligned}
$$

where $m=$ volume fraction of moisture saturation

$E_{a}=$ emanation coefficient at dryness

$E_{w}=$ emanation coefficient at saturation

$m^{\star}=$ minimum moisture on plateau of emanation/moisture curve

The constants $m^{\star}, E_{a}$ and $E_{w}$ are constants from the emanation model.

The one-dimensional, steady-state diffusion of radon through a moist, unsaturated earthen material can be described as the combined diffusion in the gas- and liquid-filled pore volumes of the material. The gas-phase diffusion 
can be described by

$$
D_{a} \frac{d^{2} C_{a}}{d x^{2}}-\lambda C_{a}+\frac{R \rho \lambda E_{a i r}}{P_{a i r}}+T_{w a}=0
$$

where $D_{a}=$ the diffusion coefficient in the air-filled pore space $\left(\mathrm{cm}^{2} / \mathrm{s}\right)$

$c_{a}=$ the concentration of radon in the $\operatorname{air}\left(\mathrm{pCi} / \mathrm{cm}^{3}\right)$

$T_{\text {wa }}=$ radon transfer rate from the water to the air $\left(\mathrm{pCi} / \mathrm{cm}^{3} \mathrm{~s}\right)$

$P_{\text {air }}=$ air-filled porosity, $=P(1-m)$

The corresponding equation for diffusion in the liquid-filled pore region is:

$$
D_{w} \frac{d^{2} D_{w}}{d x^{2}}-\lambda C_{w}+\frac{R \rho \lambda E_{\text {water }}}{P_{\text {water }}}-T_{\text {wa }}=0
$$

where $D_{w}=$ the diffusion coefficient in the water filled pore spaces $\left(\mathrm{cm}^{2} / \mathrm{s}\right)$

$c_{w}=$ the concentration of radon in the water-filled space $\left(\mathrm{pCi} / \mathrm{cm}^{3}\right)$

$P_{W}=$ water-filled porosity $=P m$.

It is assumed that $D_{a}$ and $D_{w}$ are spatially independent. The radon concentration in the total pore space is the volume-weighted average concentrations in the air and water components. It is given from the previous definitions of $C_{a}$ and $C_{w}$ by

$$
c=c_{a}(1-m)+c_{w} m
$$

Equation (15) provides the basis for describing radon diffusion in the combined air and water phases of the pore space. If Eq (14a) is multiplied 
by (1-m) and Eq (14b) is multiplied by $m$ and then the two equations are summed, the result is

$$
D_{a} \frac{d^{2} C_{a}(1-m)}{d x^{2}}+D_{w} \frac{d^{2} C_{w} m}{d x^{2}}-\lambda C_{a}(1-m)-\lambda C_{w} m+\frac{R \rho \lambda}{P}\left(E_{a i r}+E_{w a t e r}\right)=0
$$

In forming the combined equation it is assumed that $\mathrm{m}$ is spatially independent. It is also noted that the radon transfer rate cancels, because a transfer from water to air in the pore space is no longer a source or a sink term. The dispersion term is used to define the combined $D$.

$$
D C=D_{a} C_{a}(1-m)+D_{w} C_{w} M .
$$

The resulting total pore diffusion equation, assuming intimate mixing of the air and water, but no total passage blockage by water, is given by

$$
D \frac{d^{2} C}{d x^{2}}-\lambda C+R \rho \lambda E / P=0
$$

The diffusion coefficient $D$, which represents the combined "real-world" diffusion coefficient of the unsaturated pore, depends on the relative volumes of air and water in the pore space, and on their physical configurations. In principle, $D$ is a function of $m, D_{A}$ and $D_{W}$; however, the functional relationship is complicated and has not been defined. It has been approximated with a model using combinations of unblocked and water-blocked pores, however, that is described in the following section. 


\section{PORE MODEL DEVELOPMENT}

In order to mathematically describe the diffusion of radon through a porous medium, the medium must be characterized with respect to (a) the pore fluid and (b) the pore structure. This section provides the basis for characterizing earthen materials in both of these respects. The characterization makes use of configurational models, but is based directly on measured physical parameters of the earthen materials.

Several soil parameters are potentially related to radon diffusion coefficients and could potentially be used as a basis for a diffusion model. These include moisture, bulk density, total porosity, air-filled porosity, pore size distribution, grain size distribution, air permeability, hydraulic conductivity, internal surface area, and perhaps others. Since many of these parameters are interrelated, only those providing a unique contribution to the material description were utilized. The following model development is based only on the moisture content and the pore size distribution of the earthen material. Other parameters needed in the calculations can be derived from these. For example, the total porosity is obtained by integrating the pore size distribution; and the bulk density $(\rho)$ can be calculated from the total porosity $(P)$ by assuming

a typical specific gravity $(\mathrm{SG})$ for western cover materials of $2.7 \mathrm{~g} / \mathrm{cm}^{3}$,

$$
\rho=S G(1-P)
$$

\section{Pore Fluid Configuration}

The pore fluid is composed of water and air, whose relative volumes are defined by the moisture content and total porosity of the soil. The configuration of the water-air mixture in the pores is extremely important in its impact 
on the diffusion coefficient of the pores. Two extreme water-air configurations are illustrated in Figure 2, as represented by $D_{u}$ and $D_{b}$. The $D_{u}$ configuration assumes the water to occur as a film covering the surface of the pore, but not blocking its central air-filled channel. This configuration is probably a good approximation of the major pores in a soil. The small intragranular pores become saturated first, leaving the larger intergranular pores with moist or water-covered surfaces. The radon diffusion coefficient for the $D_{u}$ configuration is given by

$$
D_{u}=\frac{D_{a}}{1+\frac{m k}{1-m}}+\frac{D_{w}}{1+\frac{1-m}{m k}} \text {, }
$$

where $k=$ radon distribution coefficient for water/air

$$
\left(k=0.26 \text { at } 20^{\circ} \mathrm{C}\right)
$$

The u subscript refers to the fact that the total passage is unobstructed by water blockages as illustrated in Figure 2.

Equation 19 can also be shown to be valid for a hypothetical, homogeneous mixture of air and water in a pore, which is mathematically equivalent to the surface-film configuration $D_{u}$ in Figure 2. Although the air-water mixture in a pore is not likely to occur in a continuous, homogeneous configuration, the simplicity of its description makes it useful in deriving Equation 19 for the $D_{u}$ configuration.

Although many intergranular pores may be represented by the $D_{u}$ configuration, pore blockage by water, as illustrated in Figure 1, is also significant. An extreme representation of a water blocked pore is illustrated by the $D_{b}$ configuration in Figure 2. If all of the water were to occur as intermittent pore blockages, the diffusion coefficient can be estimated by solving the 
resulting multilayer system. For this case, $C_{a}=C$ in the air region and $C_{w}=c$ in the water region. Solution of the equations yields an expression of the form of Equation 17, in which the diffusion coefficient, represented by $D_{b}$, is given by

$$
D_{b}=\frac{D_{w}}{\left[m+(1-m)\left(D_{w} / D_{a}\right)^{\frac{1}{2}}\right]^{2}}
$$

Although a soil system is not comprised entirely of either unblocked or blocked pores, these two extremes define the probable maximum and minimum diffusion coefficients for a soil system. Figure 3 illustrates the relative magnitudes of the unblocked $\left(D_{u}\right)$ and blocked $\left(D_{b}\right)$ pore diffusion coefficients in comparison with measured diffusion coefficients reported for a variety of soils. As this comparison suggests, soil pores can be described by a combination of unblocked and blocked pores. The value of $D$ for a particular unconsolidated material depends upon the physical configuration of the pore spaces as well as other factors. If the configuration is such that significant pore blockage occurs with relatively little moisture, then the $D$ value will tend to be closer to $D_{b}$. Conversely, if the soil can absorb a relatively large quantity of water before pore blockage occurs, then the value of $D$ will be closer to $\mathrm{D}_{\mathrm{u}}$.

In general unconsolidated earthen materials have pore spaces randomly distributed in volume and location; thus, a random, statistical analysis of pore configuration is suggested and is described in the next section. Certain geological samples may be characterized by a quasi-ordered pore configuration and their analysis must be modified accordingly.

The value of $\mathrm{D}_{\mathrm{a}}$ used in Equations 19 and 20 includes the effect of the air-filled pore diameter. As the pore diameter decreases, Knudsen diffusion 


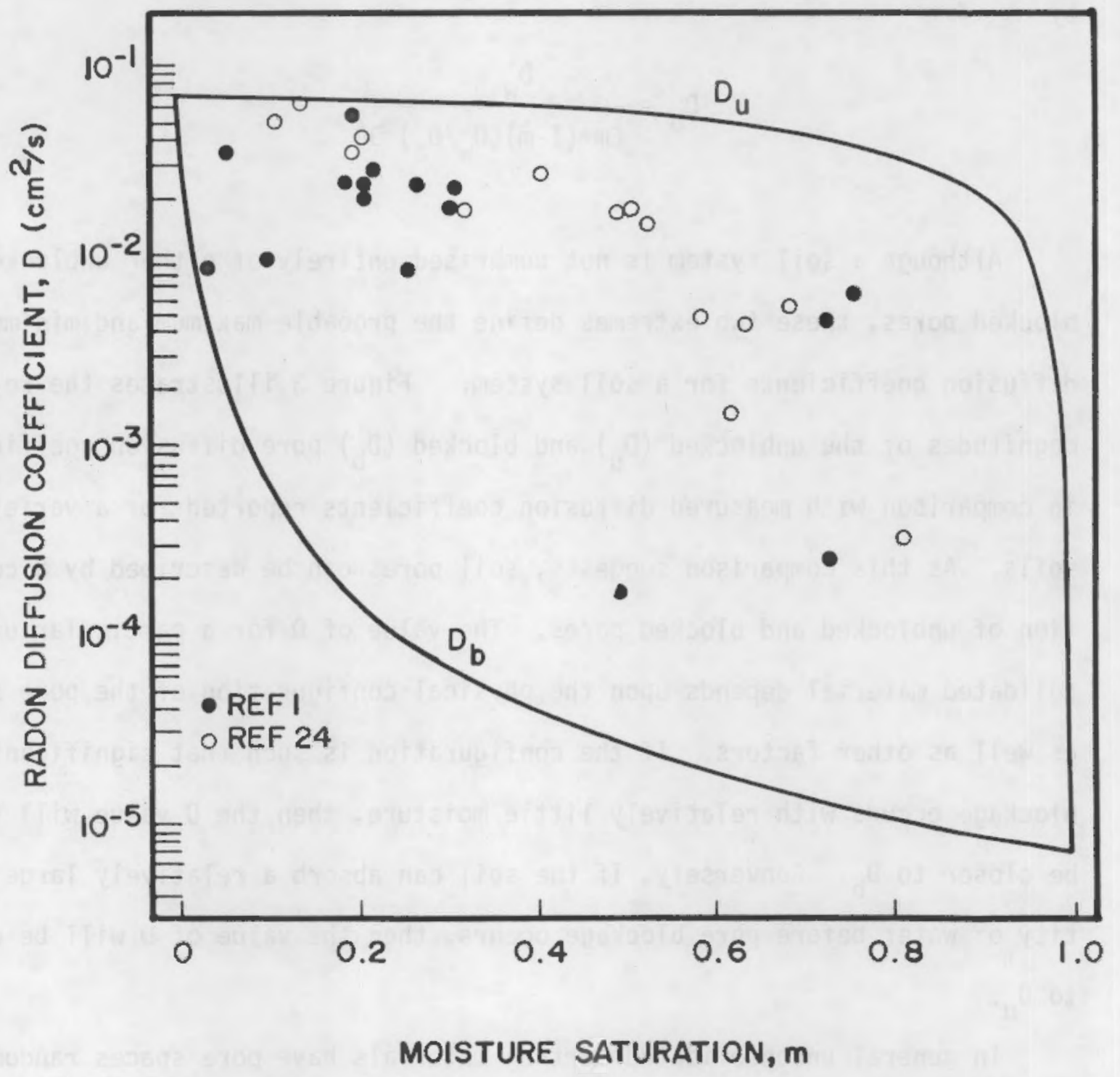

RAE - 100363

FIGURE 3. COMPARISON OF DIFFUSION COEFFICIENTS FOR WATER-BLOCKED PORES, $D_{b}$, AND UNBLOCKED PORES, $D_{u}$, WITH MEASURED DIFFUSION COEFFICIENTS. 
becomes dominant. (35) The expression for $D_{a}$ which includes the Knudsen and transition realm is: $(36)$

$$
\frac{1}{D_{a}}=\frac{1}{\tau \bar{D}_{k}}+\frac{1}{\tau D_{0}}
$$

where

$$
\begin{aligned}
& D_{k}=\text { Knudsen diffusion coefficient }=1.12 r \\
& r=\text { radius of air-filled space in pore }(\mu \mathrm{m})
\end{aligned}
$$

In addition to describing the physical configuration of the water in pore spaces, the sequence in which pores of various sizes absorb water must also be defined. It is recognized that capillary effects cause small pores to absorb water before large pores. However, since large pores are usually intergranular and are lined by smaller pores, the large pores may also contain an effective film of water prior to the saturation of the smaller pores.

The pore filling sequence chosen for the present model was therefore defined by considering a water film of uniform thickness to be present in all pores. The film thus caused a greater degree of saturation in small pores than in large ones. When the water film thickness equalled or exceeded the radius of a measured pore size increment, that increment was considered saturated. Additional water from thicker films was added only to the pore size increments which were still unsaturated. The volumetric saturation of a soil system was therefore calculated from a given water film thickness and pore size distribution as

$$
m=\frac{\sum v_{i}\left[1-\left(r_{i}-w\right)^{2} / r_{i}{ }^{2}\right]}{\sum_{i} v_{i}},
$$


where

$$
\begin{aligned}
v_{i}= & \text { incremental volume of pores of radius } r_{j} \text { (the } \\
& \text { measured pore size distribution) } \\
w= & \text { the assumed water film thickness }(\mu \mathrm{m})
\end{aligned}
$$

Ideally, Equation 22 should express $w$ as a function of $m$. Since the equation cannot be explicitly solved in this form, however, the value for $w$ at a given $\mathrm{m}$ is determined by successive approximation.

An additional refinement was included in the above pore-filling sequence. This was to account for the fact that an extremely small air-filled opening is not stable in a water-filled annulus. Instead, the water will completely block or saturate a pore segment when $w$ is almost as large as $r_{i}$. The minimum radius of an air-filled opening in a pore was estimated from the pressurecurvature relationships which characterize capillary effects. By combining the bubble pressure-radius relationship ${ }^{(37)}$ with the capillary suction expression for a pore, ${ }^{(38)}$ the following relationship was derived:

$$
r_{c}=\left(0.7+1 / r_{i}\right)^{-1}
$$

where $\quad r_{c}=$ the minimum radius of curvature of an air-filled region of a pore $(\mu \mathrm{m})$ $r_{i}=$ the pore radius $(\mu \mathrm{m})$

Using the above descriptions of water configuration, a radon diffusion coefficient can be calculated for any pore size increment at any moisture content using Equation 19 and Equation 22. Although Equation 19 only considers unblocked pores ( $D_{u}$, Figure 2 ), the effect of pore blockage by water is considered by combining saturated pore segments in series with unsaturated segments. 
The method of combining the diffusion coefficients for each pore size increment is presented in the following section.

\section{Pore Structure}

The manner in which the pore structure of the earthen material is modelled from the measured pore size distribution is critical in obtaining the proper diffusion coefficient-moisture relationship. For example, a model which assumes the distribution of pores to consist of parallel cylindrical tubes of various diameters has been reported. $(32,36)$ However, the radon diffusion coefficients predicted by such a model resemble the $D_{u}$ curve in Figure 3 , overestimating the diffusion coefficients for most soils due to the dominance of the large pores. Converging or diverging composite pores which incorporate all pore sizes in series have also been proposed. ${ }^{(36)}$ However, the early blockage of the small pores as moisture is added to the composite series retards diffusion in the entire pore, resulting in low diffusion coefficients, similar to the $D_{b}$ line in Figure 3.

A completely random pore combination model was used to describe the earthen materials in this work. It was recognized that all sizes of pores may be interconnected to each other, and that some diffusion paths may resemble straight cylinders while others may resemble narrow-necked chambers which would suffer from intermittent water blockage. The measured pore size distribution was therefore combined statistically to produce all possible combinations of single and composite pores. A simplified example of the model pore combinations is illustrated for a three-component pore size distribution in Figure 4 . In cases of composite pores, the relative heights of each segment were determined from the relative total lengths of the given pore components as calculated from the 
pore size distribution. The total length of each pore size increment was calculated as

$$
h_{i}=\frac{v_{i}}{\pi r_{i}^{2}} \text {. }
$$

The diffusion coefficients determined for each pore or pore segment were combined in all single and composite pore combinations, and the resulting pores, as illustrated in Figure 4, were considered to exist in parallel in the actual soil. As illustrated, composite pores provided more possible combinations than single pores, and were weighted with a greater total volume. Typically, nine pore size increments were incorporated in calculating a radon diffusion coefficient.

The diffusion coefficients for each of the composite pores $\left(D_{c p}\right)$ were calculated from the diffusion coefficients of their segments using the weighting function

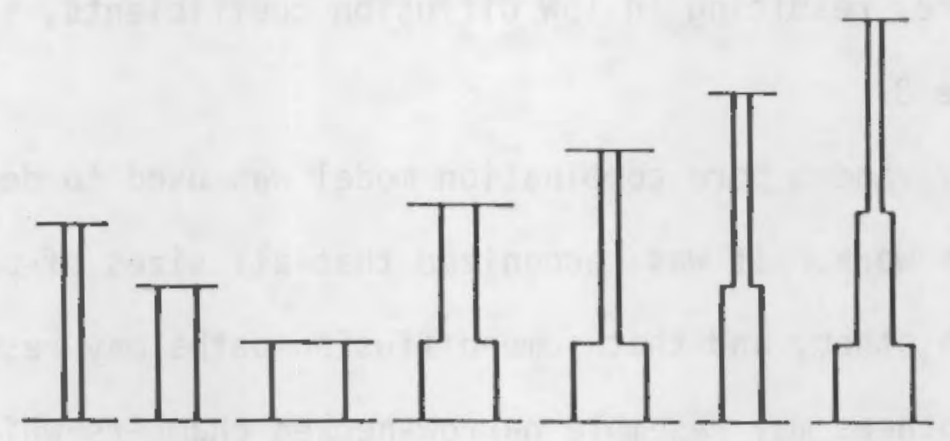

RAE-100171

FIGURE 4. ILLUSTRATION OF PORE COMBINATIONS FOR A THREE-COMPONENT PORE SIZE DISTRIBUTION 


$$
D_{C P}=\underset{i}{\left[\Sigma f_{i} /\left(D_{u i}\right)^{\frac{3}{2}}\right]^{-2}}
$$

where $\quad f_{i}=$ the fractional height of the pore segment in the composite pore

$D_{u i}=$ The individual segment diffusion coefficients calculated from Equation 19

The resulting diffusion coefficients for all possible single and composite pores were then weighted according to the volume or combined volumes of the given pore sizes to estimate the average diffusion coefficient for the pores of the earthen material:

$$
\begin{aligned}
& D=\frac{\sum\left(D_{\mathrm{cpj}} \sum_{j}^{k} v_{i}\right)}{k}, \\
& \sum \sum v_{j}
\end{aligned}
$$

where $\quad D=$ the effective radon diffusion coefficient of the material, as defined by Equation 2 and Equation 8.

$j=$ subscript referring to each single or composite pore.

$i=$ subscript referring to each incremental pore size.

$k=$ number of size increments in composite pore $j$.

\section{PORE MODEL APPLICATION}

The above pore structure and moisture models were tested and evaluated using a computer code to calculate radon diffusion coefficients from the pore size distribution and moisture contents of various soils. This section 
describes the determination of the soil parameters required for these calculations and the computer code used for the calculations, and compares the results with published correlations and measured diffusion coefficients.

\section{Determination of Soil Parameters}

Soil moisture content is a widely measured parameter which has been used previously to predict diffusion coefficients. ${ }^{(22,29)}$ It is accurately determined by gravimetric methods and is usually expressed as a dry weight percentage. The volumetric moisture saturation, $\mathrm{m}$, is determined from the dry weight percentage (M) as

$$
m=\frac{M p}{P}
$$

The pore size distribution depends on the particle size and compaction of the earthen material, and can be estimated from these parameters or measured by mercury intrusion porosimetry or, for smal1 pores, by gas adsorption characteristics. ${ }^{(39)}$ The pore size distribution is often more conveniently determined from water retention characteristic curves $(38,40)$ which are measured to define the hydrologic properties of soil systems. In making these estimates the following relationship is used to relate pore radius to capillary pressure:

$$
r_{i}=-\frac{1480}{\psi}
$$

where $\quad r_{i}=$ pore radius in $\mu m$

$\Psi=$ soil capillary pressure in $\mathrm{cm}$ of water 
Procedures for differentiating the water retention curve are similar to those used with mercury intrusion porosimetry curves.

The direct calculation of pore size distributions from grain size and density data is theoretically attractive because of the common availability of sieve analyses and compaction data. Attempts have been made to relate grain size distributions to a pore size distribution index ${ }^{(41)}$ in estimating hydraulic conductivities of soils. A more recent report has given a more direct correlation of pore size and grain size distribution parameters. (42) It is expected that such applications of direct pore size distribution calculations may yield data of sufficient accuracy for diffusion coefficient calculations, particularly in the absence of more reliable water retention curve data.

The tortuosity is primarily a function of the soil porosity and of the width of its pore size distribution. Although natural soils are often well represented by the constant value $\tau=0.66$, a more detailed calculation is used in the present model to accommodate the wide range of parameters being considered. The determination of $\tau$ is partially based on considerations of uniform packed spheres, from which the following relationship with porosity was derived:

$$
\tau=\left\{1+\left[\frac{3(1-P)}{2 \pi}\right]^{2 / 3}\right\}^{-1}
$$

This equation accounts for the less-tortuous diffusion pathway which occurs when uniform spheres are less-densely packed, and reaches the most tortuous value, $\tau=.66$ for the close-packed geometry when $P=0.26$.

When spheres of different sizes are mixed, small spheres may fill voids between larger spheres. In close-packed geometry, a binary mixture of very large and very sma11 spheres would have the tortuosity of each size superimposed, 
resulting in a combined tortuosity of $\tau=(0.66)^{2}$. If three very different sizes were mixed, the exponent could become 3 , or in general, equal to the width of the grain size distribution normalized to the ratio of inscribed sphere radii. This ratio is 11.3 for close-packed spheres, and using the grain-size to pore-size model of Arya and Paris, ${ }^{(42)}$ becomes 44 if the width of the pore-size distribution is used instead of that for the grain size distribution. The resulting tortuosity expression used in the following diffusion model calculations is

$$
\tau=\left\{1+\left[\frac{3(1-P)}{2 \pi}\right]^{2 / 3}\right\}^{-(1+2 G S D / 44)}
$$

where GSD = geometric standard deviation of the pore-size distribution

\section{Calculations}

Radon diffusion coefficients were calculated by a simple FORTRAN computer code which used a nine-increment pore size distribution and the soil density and porosity as input. The pore size distribution was first normalized to the total porosity of the soil, after which total pore lengths were computed for each pore size increment using Equation 24. A loop was then entered to calculate the radon diffusion coefficients at each of 26 different moisture contents. The moistures varied for each sample, and were determined from a corresponding array of water film thicknesses ranging from $0.001 \mu \mathrm{m}$ to $2000 \mu \mathrm{m}$. Values of $m$ were calculated from Equation 22.

At each given moisture content, a diffusion coefficient was calculated for each pore size increment using Equation 19. When the air-filled volume of the pore had a small $(<10 \mu \mathrm{m})$ radius, the resulting diffusion coefficient was reduced accordingly with Equation 21 to account for Knudsen and transitional 
diffusion. If the air-filled radius of the pore was smaller than the critical radius of curvature for the given pore size (Equation 23), the pore increment was considered saturated, and assigned a diffusion coefficient equal to $D_{w}$. When the diffusion coefficient was defined for each pore size increment, the diffusion coefficients for all possible single and composite pores were calculated using Equation 25, which is a height-weighted equation for serial pore combinations. The resulting 511 diffusion coefficients were then combined by the volume-weighting function, Equation 26, for parallel diffusion through single and composite pores. This entire calculation sequence was then repeated for a different water film thickness and continued until 26 diffusion coefficients and moisture contents had been calculated.

\section{Results}

Radon diffusion coefficients were calculated from the random pore combination model for several arbitrary pore size distributions to evaluate the sensitivity of the diffusion coefficient-moisture relationships to pore sizes. Calculated diffusion coefficients were also compared to measured diffusion coefficients for soils whose pore sizes were calculated from moisture drainage curves. The calculated diffusion coefficients were also compared to results predicted by two published correlations with porosity and moisture. The following paragraphs summarize these results.

\section{Sensitivity to Particle Size Parameters}

The sensitivity of calculated diffusion coefficients to median particle size and to the geometric standard deviation (GSD) of the pore size distribution 
was examined. Nine pore size distributions were calculated to simulate a wide range of possible soil materials. These are summarized in Table I. As indicated, the median pore diameter was held constant in six of the distributions, and the geometric standard deviation of the pore size distribution was held constant among four other distributions. The diffusion coefficients calculated from these distributions assuming a total porosity of 0.4 are plotted in Fig.. ures 5 and 6 .

As indicated in Figure 5, radon diffusion coefficients decreased with decreasing median pore size. The largest decreases were observed in the dry range, where about an order of magnitude difference in diffusion coefficient was attributed to the differences in median pore size. This difference is likely due to the dominance of Knudsen diffusion in the small pore size ranges. Typical earthen cover materials are probably best approximated by the 1-100 $\mu \mathrm{m}$ median pore size curves. The geometric standard deviation of the pore size distribution was fixed at 5.0 for these curves.

Figure 6 illustrates a similar comparison in which the geometric standard deviation of the pore size distribution was allowed to vary. As indicated, diffusion coefficients decreased systematically with increasing GSD. Typical soil materials are generally in the 2-10 range of GSD, a1though unusually well-sorted materials may exhibit even lower values. As illustrated, the wide variation in GSD of the pore sizes caused an approximate two order-of-magnitude variation in $D$.

\section{Comparison with Measured Data}

The random pore combination model was evaluated with eight sets of pore size distribution data obtained from water retention curves as described in 
Table I

Pore Size Distributions Used for Diffusion Coefficient Sensitivity Tests

\begin{tabular}{|c|c|c|c|c|c|c|c|c|c|}
\hline$\left(10^{5} \mathrm{~cm}^{3} / \mathrm{g}\right)$ & & & & & $\begin{array}{c}r_{i} \\
(u m)\end{array}$ & & & & \\
\hline 49 & 10 & 1.1 & 0.058 & 0.0063 & 0.00019 & 0.0000056 & 0.00058 & 0.0058 & 0.58 \\
\hline 422 & 10 & 1.9 & 0.21 & 0.040 & 0.0029 & 0.00020 & 0.0021 & 0.021 & 2.1 \\
\hline 2087 & 10 & 3.3 & 0.76 & 0.25 & 0.043 & 0.0075 & 0.0076 & 0.076 & 7.6 \\
\hline 5452 & 10 & 5.7 & 2.8 & 1.6 & 0.66 & 0.27 & 0.028 & 0.28 & 28 \\
\hline 7509 & 10 & 10 & 10 & 10 & 10 & 10 & 0.10 & 1.0 & 100 \\
\hline 5452 & 10 & 17 & 36 & 63 & 152 & 366 & 0.36 & 3,6 & 360 \\
\hline 2087 & 10 & 30 & 131 & 398 & 2,310 & 13,400 & 1.31 & 13.1 & 1,310 \\
\hline 422 & 10 & 53 & 480 & 2,510 & 35,100 & 490,000 & 4.8 & 48 & 4,800 \\
\hline 49 & 10 & 92 & 1,720 & 15,800 & 533,000 & $17,900,000$ & 17.2 & 172 & 17,200 \\
\hline Median $r$ & 10 & 10 & 10 & 10 & 10 & 10 & 0.1 & 1 & 100 \\
\hline GSO & 1 & 2 & 5 & 10 & 30 & 90 & 5 & 5 & 5 \\
\hline
\end{tabular}




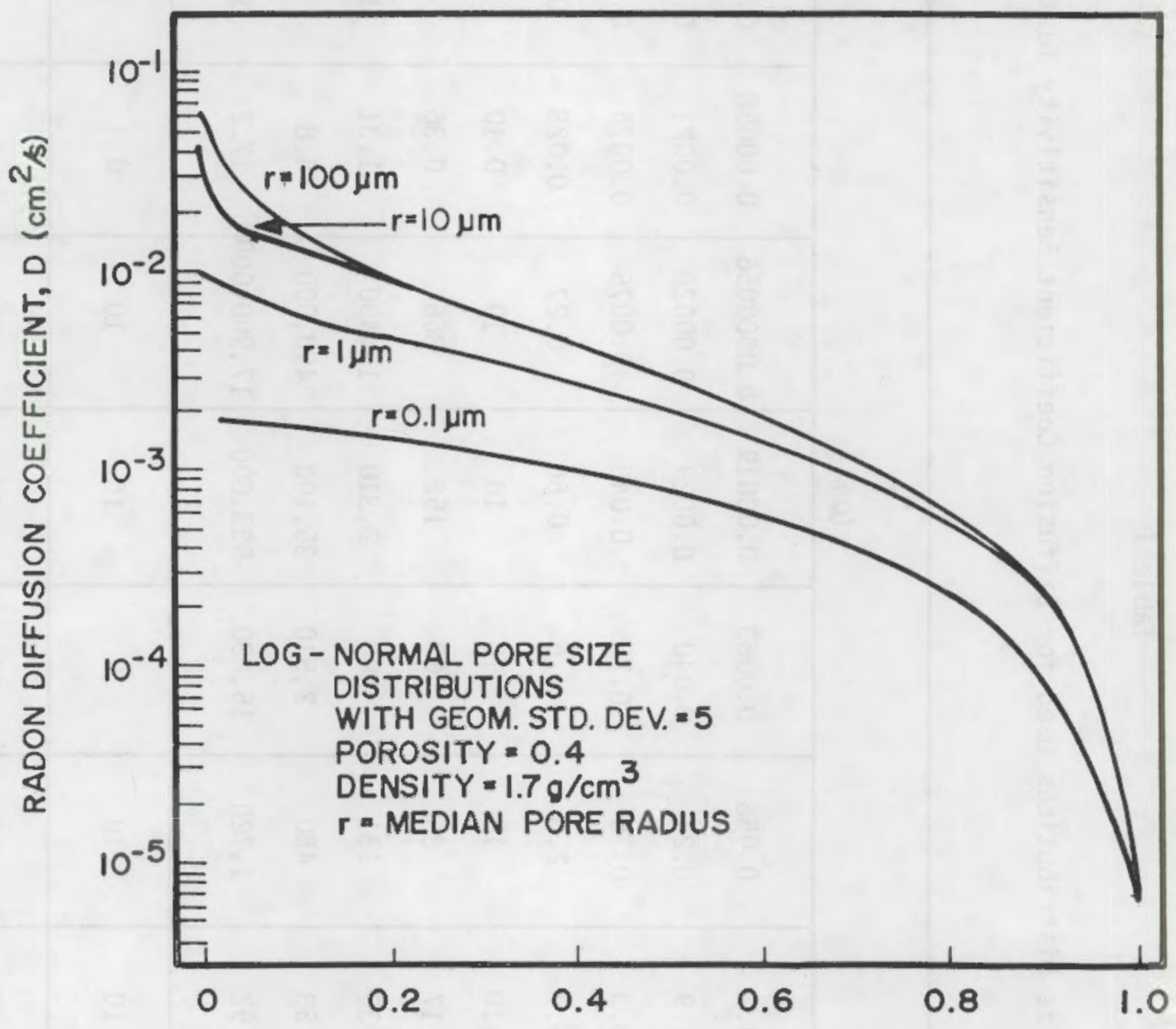

MOISTURE SATURATION, $m$

RAE - 100360

FIGURE 5. COMPARISON OF DIFFUSION COEFFICIENT MOISTURE CURVES FOR VARIOUS MEDIAN PORE SIZES. 


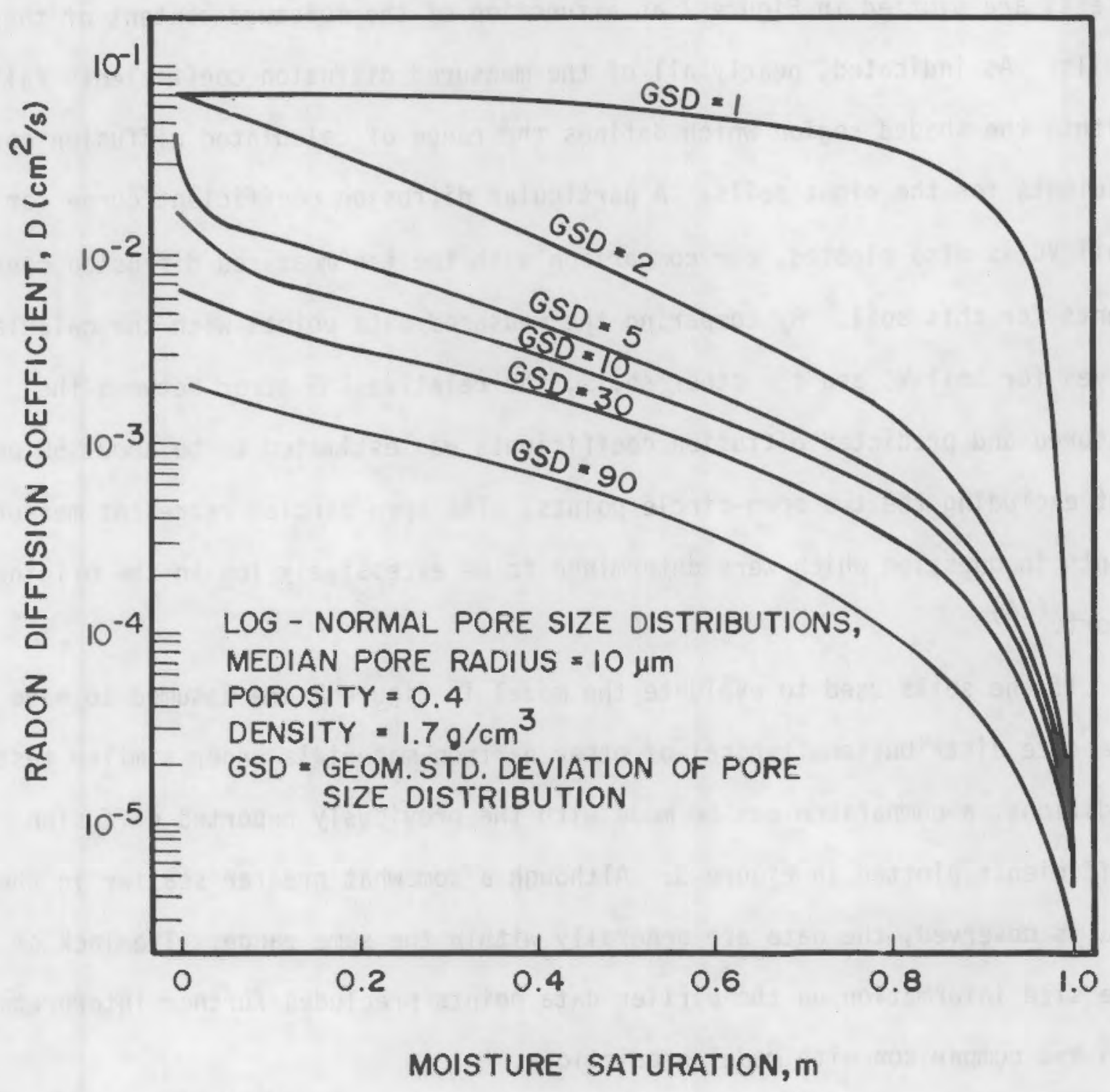

RAE - 100361

FIGURE 6. COMPARISON OF DIFFUSION COEFFICIENT - MOISTURE CURVES FOR VARYING WIDTHS OF PORE SIZE DISTRIBUTIONS. 
Reference 38. The water retention curves and measured diffusion coefficients, for comparison, were taken primarily from Reference 24 with some additional measurements made as part of the present work. The measured diffusion coefficients are plotted in Figure 7 as a function of the moisture content of the soils. As indicated, nearly all of the measured diffusion coefficients fall within the shaded region which defines the range of calculated diffusion coefficients for the eight soils. A particular diffusion coefficient curve for soil VC is also plotted, for comparison with the ten measured diffusion coefficients for this soil. By comparing the measured data points with the calculated curves for soil VC and the other soils, the relative RMS error between the measured and predicted diffusion coefficients was estimated to be about 50 percent excluding the two open-circle points. The open circles represent measured points in question which were determined to be excessively low in the original report. (24)

If the soils used to evaluate the model in Figure 7 are assumed to have pore size distributions typical of other earthen materials under similar test conditions, a comparison can be made with the previously reported diffusion coefficients plotted in Figure 3. Although a somewhat greater scatter in the data is observed, the data are generally within the same range. The lack of pore size information on the earlier data points precludes further interpretation and comparison with model predictions.

Comparison with Published Correlations

Two simple correlations have been reported for estimating radon diffusion coefficients from moisture or air-filled porosity. These are based on the fact that for western soils with low moisture contents, most of the measured values 


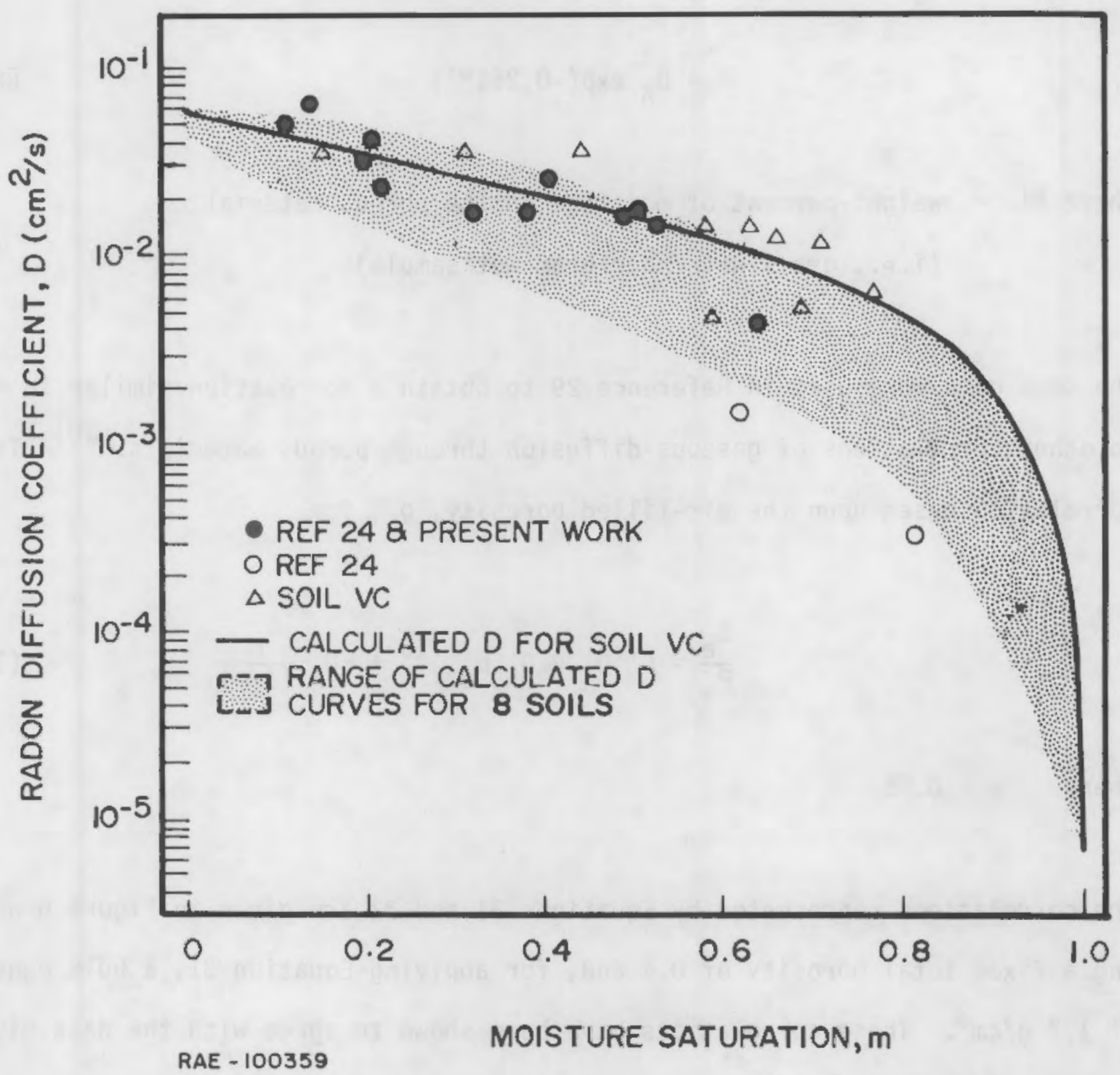

FIGURE 7. COMPARISON OF MEASURED RADON DIFFUSION COEFFICIENTS WITH CALCULATED VALUES. 
of $D$ at a given $m$ are within a factor of 3 of each other.

It was reported in Reference 22 that the diffusion coefficients for a wide variety of western soils could be approximated by the following simple correlation involving moisture and the diffusion coefficient of radon in air:

$$
D=D_{A} \exp \left(-0.261 M^{\prime}\right) \text {, }
$$

where $M^{\prime}=$ weight-percent of moisture in the porous material (i.e., grams water per gram wet sample)

The same data were used in Reference 29 to obtain a correlation similar in form to other correlations of gaseous diffusion through porous materials. (30) The correlation based upon the air-filled porosity, $p_{a}$, is:

$$
\frac{D_{e}}{P_{a}}=D^{\prime} D .74 D_{A} P_{a}^{1.16}+\tau D_{W} \frac{m}{(1-m)}
$$

where $\tau=0.66$

The correlations represented by Equations 31 and 32 are given in Figure 8 assuming a fixed total porosity of 0.4 and, for applying Equation 31, a bulk density of $1.7 \mathrm{~g} / \mathrm{cm}^{3}$. These correlations have been shown to agree with the data given in Figure 3 and 1 ie well within the bounds defined by the $D_{u}$ and $D_{b}$ curves, which are also shown in Figure 8 . It should be noted that the $A$ and $B$ curves will be shifted for different values of $P$ and $\rho$, and that the plotted curves are merely typical of these soil parameters.

Since the correlations were estimated from a variety of measured diffusion coefficients without regard to pore size distributions, specific comparisons 


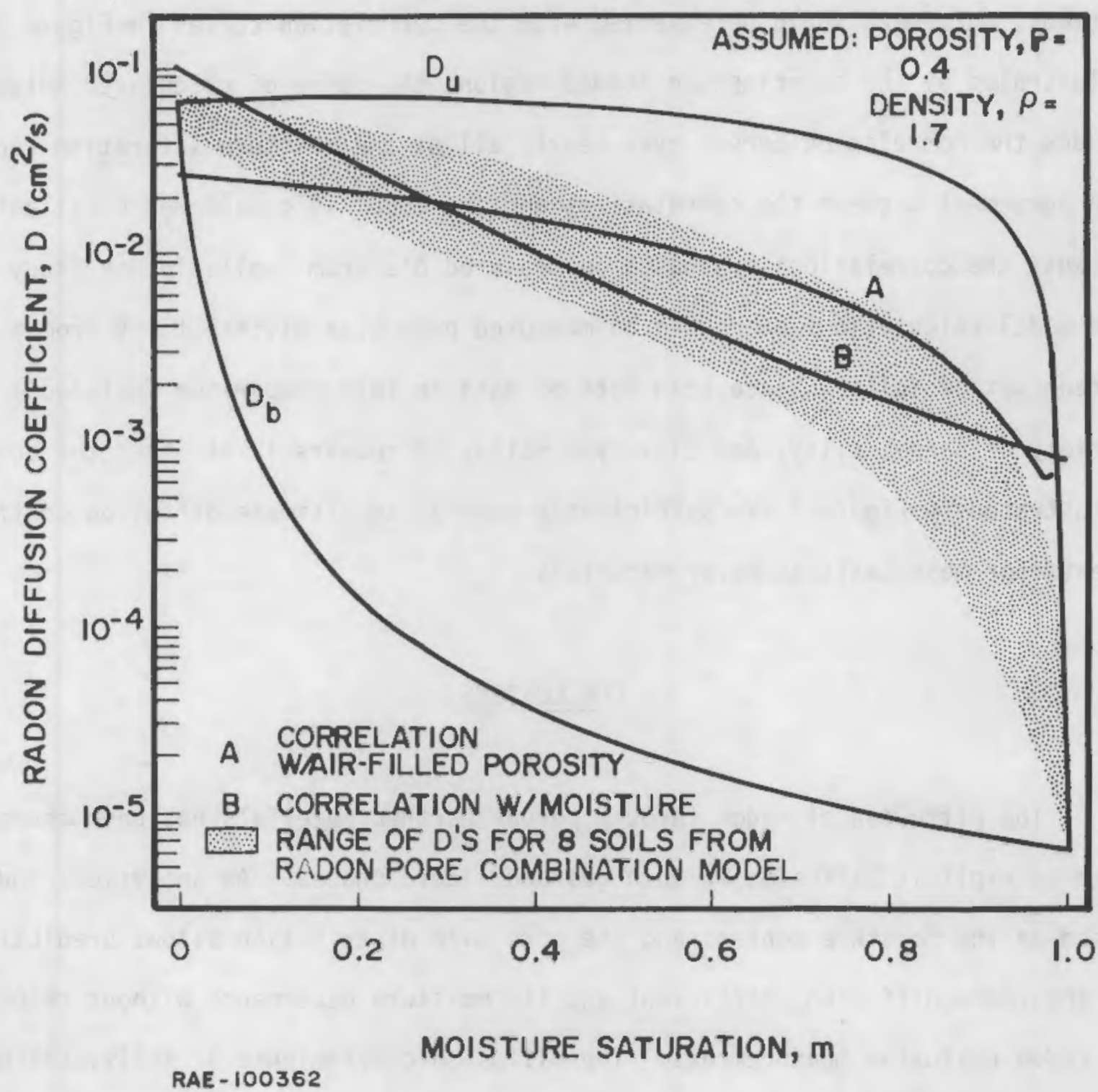

FIGURE B. COMPARISON OF DIFFUSION COEFFICIENTS FOR WATER-BLOCKED PORES, $D_{b}$, AND UNBLOCKED PORES, $D_{u}$, WITH EMPIRICAL CORRELATIONS WITH AIR-FILLED POROSITY (A) AND MOISTURE (B), AND WITH THE RANGE OF CALCULATED D'S FOR EIGHT SOILS. 
cannot be made with the random pore combination model. However, if the range of coefficients calculated from the random pore combination model illustrated in Figure 7 is assumed to be representative of the soils used in deriving the correlations, agreement would be expected with the correlation curves in Figure 8 . As illustrated by the superimposed shaded region, the range of calculated values includes the correlation curves over nearly all of the moisture saturation range. The agreement between the correlations and the model is considered excellent because the correlations are based on measured D's from soils in one study and the model calculations are based on measured pore size distributions from a different set of soils. Since both sets of data in this comparison included a wide variety of sandy, silty, and clay-type soils, it appears likely that the curves illustrated in Figure 8 are sufficiently general to estimate diffusion coefficients for most tailings cover materials.

\section{CONCLUSIONS}

The diffusion of radon through porous earthen materials has been characterized by explicit diffusion in both gas and liquid phases. An analytical model based on the moisture content and the pore size distribution allows prediction of the radon diffusion coefficient and its moisture dependence without resorting to radon diffusion measurements. The diffusion coefficients of individual pore segments can be represented by simple functions of their moisture and air contents, which can in turn be used to calculate diffusion coefficients of more complicated pores. The effect of moisture on the radon diffusion coefficients is greater than can be simply explained by porosity considerations, and must rely on the diffusion of radon through short water pathways in some of the interconnecting pores. 
The pore size distribution of an earthen material was found to markedly affect both the magnitude and the moisture dependence of its radon diffusion coefficient. A random pore combination model was found to give a suitable representation of the actual soil pore structure for the purpose of predicting radon diffusion coefficients. The pore structure must include all possible combinations of the increments in the pore size distribution, properly weighted, in order to adequately represent the actual pore channels in which radon diffusion occurs.

Radon diffusion coefficients are lower in soils having low median pore diameters than in soils with higher median pore diameters. This dependence on median pore size is greatest at low moisture contents. Soils with extremely uniform pore sizes (geometric standard deviation of pore sizes <2) are predicted to have significantly higher diffusion coefficients than soils with broader pore size distributions.

The random pore combination model was shown to predict radon diffusion coefficients with a relative uncertainty on the order of 50 percent for six soils. Further studies with a greater variety of soils will establish more conclusively the precision and accuracy of this model. The model was also shown to be in excellent agreement with previously reported correlations of diffusion coefficients with moisture and air-filled porosity. 


\section{LITERATURE REFERENCES}

1. V.C. Rogers, et a1., "Characterization of Uranium Tailings Cover Materials for Radon Flux Reduction," NUREG/CR-1081, March 1980.

2. "Generic Environmental Impact Statement on Uranium Milling Project M-25," U.S. Nuclear Regulatory Commission, NUREG-0706, Appendix P, 1980, Vol. 3.

3. Allan B. Tanner, "Radon Migration in the Ground: A Review," The Natural Radiation Environment, J.A.S. Adams and W.M. Lowder, Eds., University of Chicago Press, 1964.

4. G.E. Harrison, "The Diffusion of Radon Gas Mixtures," University of Birmingham, 1938.

5. E.M. Kovach, "Meteorological Influences upon the Radon-Content of SoilGas," Transaction, American Geophysical Union, 26, No. II, 1945.

6. B.J. Giletti and J.L. Kulp, "Radon Leakage from Radioactive Minerals," Columbia University, 1954.

7. S.L. Jaki and V.F. Hess, "A Study of the Distribution of Radon, Thoron, and Their Decay Products Above and Below the Ground," Fordham University, 1958.

8. H.B. Evans, "Factors Influencing Permeability and Diffusion of Radon in Synthetic Sandstones," University of Utah, 1959.

9. H.W. Kraner, G.L. Schroeder, and R.D. Evans, "Measurements of the Effects of Atmospheric Variables on Radon 222 Flux and Soil-Gas Concentration," The Natural Radiation Environment, J.A.S. Adams and W.M. Lowder, Eds., University of Chicago Press, 1964.

10. V.V. Alekseyev (ed), "Radiometric Methods in the Prospecting and Exploration of Uranium Ores," SSSR, Ministerstvo Geologic i Okhrany Nedr. Moscow: Gosgeoltekhizdat, 1957. 
11. H.W. Kraner, G.L. Schroeder, and R.D. Evans, "Annual Progress Report to AEC," MIT-952-4, 1967.

12. Wilkening, M.H. and J.E. Hand, "Radon Flux at the Earth-Air Interface," J. Geophys. Res. 65, 3367-3370, 1960.

13. Wilkening, M.H., W.E. Clements, and D. Stanley, "Radon 222 Flux Measurements in Widely Separated Regions," The Natural Radiation Environment II, J.A.S. Adams and W.M. Lowder, Eds., The University of Chicago Press, 1975.

14. M.V.J. Culot, H.G. 01son, and K.J. Schiager, "Effective Diffusion Coefficient of Radon in Concrete Theory and Method for Field Measurements, "Health Physics, 30, p. 263, March 1976.

15. K.J. Schiager, "Analys is of Radiation Exposures on or Near Uranium Mill Tailings Piles," Radiation Data and Reports, No. 7, July 1974.

16. M.V.J. Culot, H.G. 01son, and K.J. Schiager, "Radon Progeny Control in Buildings," Colorado State University, Fort Collins, Colorado, May 1973.

17. J.C. Franklin, et al., "Effects of Moisture on Radon Emanation," U.S. Bureau of Mines Technical Progress Report, $197 \mathrm{~B}$.

18. R.C. Bates and J.C. Edwards, "Radon Emanation Relative to Changing Barometric Pressure and Physical Constraints," Second Conference on Uranium Mining Technology, Reno, Nevada, November 1978. Univ. of Nevada, School of Mines, Reno, NV.

19. A.B. Tanner, "Radon Migration in the Ground--A Supplementary Review," The Natural Radiation Environment III, T.F. Gesell and W.M. Lowder, eds., CONF-780422, 1980.

20. A.S. Serdyukova and Yu. T. Kapitanov, "Radon Isotopes and Short Lived Products of Their Disintegration in Nature," Atomizdat, Moscow, 1969, (Translated in 1978). Translation \#T72-51014. 
21. P.J. Macbeth, et al., "Laboratory Research on Tailings Stabilization Methods and Their Effectiveness in Radiation Containment, "Department of Energy Report GJT-21, April 1978.

22. V.C. Rogers, R.F. Overmyer, and K.K. Nielson, "Radon Attenuation Through Cover Materials," Symposium on Uranium Mill Tailings Management, Fort Collins, Colorado, November, 1979. Colorado State Univ. Dept. of Civil Eng.

23. V.C. Rogers, et at., "A New Laboratory Technique for Measuring Diffusion Coefficients of Mill Tailings Cover," Trans. Am. Nucl. Soc. 34, p. 132 , (1980).

24. K.K. Nielson, et al., "Laboratory Measurements of Radon Diffusion Through Multilayered Cover Systems for Uranium Tailings," U.S. DOE, Report UMT/ 0206, December, 1981.

25. M.H. Momeni, et al., "Radiological Impact of Uranium Tailings and Alternatives for Their Management," Proceedings of the Health Physics Society 12th MidYear Topical Symposium, "Low-Level Radioactive Waste Management," U.S. EPA 520/3-79-002, February, 1979.

26. W.B. Silker and P.G. Heasler, "Diffusion and Exhalation of Radon from Uranium Tailings, "Battelle Pacific Northwest Laboratory, NUREG/CR-1138, PNL-3207, October, 1979.

27. J.N. Hartley and G.W. Gee, "Uranium Mill Tailings Remedial Action Program Joint Field Test," in Uranium Mill Tailings Management - IV, Fort Collins, Colorado State University, p. 115-134, (1981).

28. G.W. Gee, J.T. Zellmer, M. Dodson, R. Kirkham, B. Opitz, D. Sherwood, and J. Tingey," Radon Control by Multilayer Earth Barriers," in Uranium Mil1 Tailings Management - IV, Fort Collins, Colorado State University, p. 289-308 (1981).

29. R.W. Nelson, G.W. Gee and C.A. Oster, "Radon Control by Multilayer Earth Barriers," Symposium on Uranium Mill Tailings Management, Fort Collins, Colorado, November, 1980, Coloraco Staie Univ. Cept. of́ Civil Engineering. 
30. E. Buckingham, "Contributions to Our Knowledge of the Aeration of Soils," U.S. Department Agr. Bureau of Soils Bulletin No. 25, 1904.

31. W. Hirst and G.E. Harrison, Proc. Roy. Soc. London, A169, p. 573, 1939.

32. M. Wilkening, "Radon Transport Processes Below the Earth's Surface," The Natural Radiation Environment III, T.F. Gesell and W.M. Lowder, eds., CONF-780422, 1980.

33. B.L. Cohen, Nucl. Inst. Meth. 164, p. 595, 1979.

34. B.J. Thamer, K.K. Nielson and K.M. Felthauser, "Effects of Moisture on Radon Emanation and Diffusion," Reports to U.S. Bureau of Mines, FBDU-315-1, January, 1980, and FBDU-315-2, July, 1981.

35. M. Knudsen, Ann. Phys., 28, p. 75, 1909.

36. G.R. Youngquist, "Diffusion and Flow of Gases in Porous Solids," in Flow Through Porous Media, Am. Ch. Soc., 1970.

37. W.J. Moore, "Physical Chemistry," Englewood Cliffs, New Jersey: PrenticeHal1, Inc., 1962, p. 727-738.

38. A.C.D. Newman and A.J. Thomasson, "Pore Size Distributions and Shrinkage Processes," J. Soil Science, 30, 415-439, 1979.

39. S. Lowe11, "Introduction to Powder Surface Area," New York, John Wiley \& Sons, 1979.

40. P.S.C. Rao., R.E. Green, L.R. Ahuja and J.in. Davidson, "Evaluation of a Capillary Bundle Model for Describing Solute Dispersion in Aggregated Soils," Soil Sci. Soc. Am. J., 40, 815-820, 1976.

41. G.W. Bloemen, "Calculation of Hydraulic Conductivities of Soils fron Texture and Organic Matter Content," Z. Pflanzenernaehr. Bodenkd. 143, 581-605, (1980). 
42. L.M. Arya and J.F. Paris, "A Physicoempirical Model to Predict the Soil Moisture Characteristics from Particle-Size Distribution and Bulk Density Data," Soil Sci. Soc. Am. J., 45, 1023-1030 (1981). 


\begin{tabular}{|c|c|c|c|c|}
\hline $\begin{array}{l}\text { NRC FORM } 335 \\
\text { (111.81 }\end{array}$ & \multicolumn{2}{|c|}{$\begin{array}{l}\text { U.S. NUCLEAR REGULATORY COMMISSION } \\
\text { BIBLIOGRAPHIC DATA SHEET }\end{array}$} & \multicolumn{2}{|c|}{$\begin{array}{l}\text { 1. REPORT NUMBER (Assigned bV DOC) } \\
\text { NUREG/CR }-2765 \\
\text { PN }=-301 \\
\text { RAE }=18-2\end{array}$} \\
\hline \multirow{2}{*}{\multicolumn{3}{|c|}{$\begin{array}{l}\text { 4. TITLE AND SUBTITLE (Add Volume No, if appropriare) } \\
\text { A Mathematical Model for Radon Diffusion in Earthen } \\
\text { Materials }\end{array}$}} & \multicolumn{2}{|l|}{ 2. (Leave bienk) } \\
\hline & & & \multicolumn{2}{|c|}{ 3. RECIPIENT'S ACCESSION NO. } \\
\hline \multicolumn{3}{|l|}{ 7. AUTHOR(S) } & \multicolumn{2}{|c|}{ 5. DATE REPORT COMPLETED } \\
\hline \multicolumn{3}{|c|}{ K. K. Nielson, II. C. Ragers } & \multicolumn{2}{|c|}{ MONTH March T YEAR 1982} \\
\hline \multirow{4}{*}{\multicolumn{3}{|c|}{$\begin{array}{l}\text { 9. PEAFORMING ORGANIZATION NAME AND MAILING ADORESS (Include Zip Codel } \\
\text { Rogers and AsSOCiates Engineering Co., P.0. Box } 330 \text {, } \\
\text { Salt Lake City, UT } 84110 \text { : Subcontractor to } \\
\text { Pacific Northwest Labs, Richland, WA } 99352\end{array}$}} & \multicolumn{2}{|c|}{ DATE REPORT ISSUED } \\
\hline & & & \multicolumn{2}{|c|}{\begin{tabular}{|l|r|} 
MONTH & October \\
\end{tabular}} \\
\hline & & & \multicolumn{2}{|l|}{ 6. (Leave blank) } \\
\hline & & & \multicolumn{2}{|l|}{ 8. (Leave blank) } \\
\hline \multirow{2}{*}{\multicolumn{3}{|c|}{$\begin{array}{l}\text { 12. SPONSORING ORGANIZATION NAME AND MAILING ADDRESS (Include Zip Code) } \\
\text { Division of Health, Siting, and Waste Management } \\
\text { Office of Nuclear Regulatory Research } \\
\text { U.S. Nuclear Regulatory Comuission } \\
\text { Washington, DC } 20555\end{array}$}} & \multicolumn{2}{|c|}{ 10. PROJECT/TASK/WORK UNIT NO. } \\
\hline & & & \multicolumn{2}{|l|}{$\begin{array}{l}\text { 11. FIN NO. } \\
\text { FIN B2269 }\end{array}$} \\
\hline \multirow{2}{*}{\multicolumn{3}{|c|}{ 15. SUPPLEMENTARY NOTES }} & \multicolumn{2}{|l|}{ D (Inclusive dares/ } \\
\hline & & & 14. (Leave blank) & \\
\hline \multirow{2}{*}{\multicolumn{5}{|c|}{$\begin{array}{l}\text { 16. ABSTAACT } 200 \text { words or less) } \\
\text { Radon migration in porous, earthen materials is characterized by diffusion in both } \\
\text { the air and water components of the system as well as by the interaction of the } \\
\text { radon between the air and water. The size distribution and configuration of the } \\
\text { pore spaces and their moisture distributions are key parameters in determining the } \\
\text { radon diffusion coefficient for the bulk material. A mathematical model is developed } \\
\text { and presented for calculating radon diffusion coefficients soley from the moisture } \\
\text { content and pore size distribution of a soil, reducting the need for resorting to } \\
\text { radon diffusion measurements. The resulting diffusion coefficients increase with } \\
\text { the median pore diameter of the soil and decrease with increasing widths of the } \\
\text { pore size distribution. The calculated diffusion coefficients are suitable for use } \\
\text { in simple homogeneous-medium diffusion experssions for predicting radon transport } \\
\text { and compare well with measured diffusion coefficients and with empirical diffusion } \\
\text { coefficient correlations. }\end{array}$}} \\
\hline & & & & \\
\hline \multirow{2}{*}{\multicolumn{5}{|c|}{$\begin{array}{l}\text { 17. KEY WORDS AND DOCUMENT ANALYSIS } \\
\text { Radon, Uranium Mill Tailings, Radon Diffusion } \\
\text { Model }\end{array}$}} \\
\hline & & & & \\
\hline \multicolumn{5}{|c|}{ 17b. IDENTIFIERS/OPEN.ENDED TERMS } \\
\hline \multirow{2}{*}{\multicolumn{2}{|c|}{$\begin{array}{l}\text { 18. AVAILABILITY STATEMENT Unlimited } \\
\text { Unt }\end{array}$}} & \multirow{2}{*}{\multicolumn{2}{|c|}{$\begin{array}{l}\text { 19. SE CURITY CLASS (This report) } \\
\text { UnCl aSS if ied } \\
\text { 20. SECURITY CLASS (This page) } \\
\end{array}$}} & 21. NO. OF PAGES \\
\hline & & & & $\begin{array}{l}\text { 22. PRICE } \\
\mathrm{S} \\
\end{array}$ \\
\hline
\end{tabular}




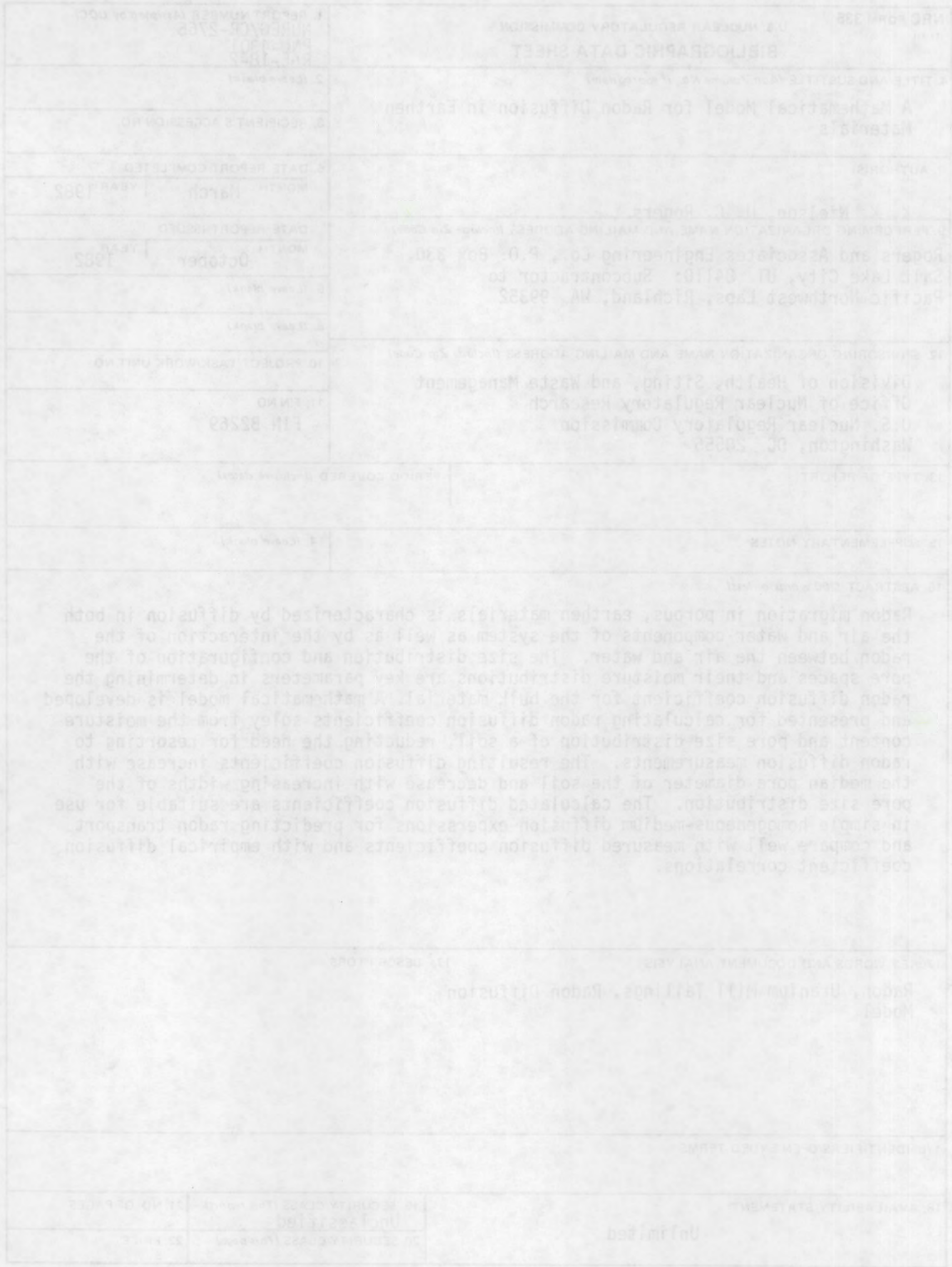

